Article

\title{
Harmful Effects of Ambient Nitrogen Dioxide on Atopic Dermatitis: Comparison of Exposure Assessment Based on Monitored Concentrations and Modeled Estimates
}

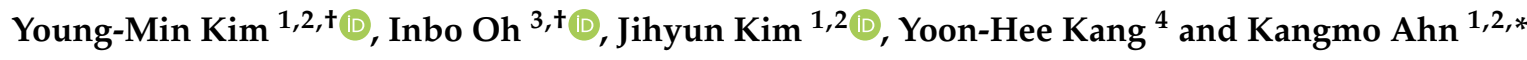 \\ 1 Environmental Health Center for Atopic Diseases, Samsung Medical Center, Seoul 06351, Korea; \\ ymkim0218@gmail.com (Y.-M.K.); narimy@hanmail.net (J.K.) \\ 2 Department of Pediatrics, Samsung Medical Center, Sungkyunkwan University School of Medicine, \\ Seoul 06351, Korea \\ 3 Environmental Health Center, University of Ulsan College of Medicine, Ulsan 44610, Korea; \\ oinbo@naver.com \\ 4 Department of Environmental Safety Engineering, Ajou University, Suwon 16499, Korea; \\ dalki1005@naver.com \\ * Correspondence: kmaped@skku.edu; Tel.: +82-2-3410-3530; Fax: +82-2-3410-0805 \\ + These authors contributed equally to the study.
}

Received: 18 August 2020; Accepted: 26 August 2020; Published: 28 August 2020

\begin{abstract}
Precise exposure assessment of air pollutants is crucial in epidemiologic studies to ensure valid estimates of health effects. We conducted a longitudinal study to evaluate the role of air quality monitoring (AQM) measurements and high-resolution modeling outcomes focusing on nitrogen dioxide $\left(\mathrm{NO}_{2}\right)$ exposure and atopic dermatitis (AD). A total of 128 young children with AD in Seoul Metropolitan Area, Korea, were recruited as a panel. We estimated the participants' exposure to $\mathrm{NO}_{2}$ for four months, from 1 April through 31 July 2014 based on (1) monitored levels from $60 \mathrm{AQM}$ stations located at varying distances from residential areas (AQM station-based $\mathrm{NO}_{2}$, $\mathrm{AQM}-\mathrm{NO}_{2}$ ) and (2) estimates from a community multi-scale air quality (CMAQ) modeling system with a high-resolution $(1 \times 1 \mathrm{~km})\left(\mathrm{CMAQ}-\mathrm{NO}_{2}\right)$. We then compared the effect of AQM-NO $\mathrm{NO}_{2} \mathrm{AD}$ symptoms with that of $\mathrm{CMAQ}-\mathrm{NO}_{2}$. The average distance between the participants' residences and the nearest AQM station was $2.03 \pm 1.06 \mathrm{~km}$, ranging from $0.28 \mathrm{~km}$ to $5.73 \mathrm{~km}$. Based on AQM-NO the AD symptoms increased by $10.28 \%$ (95\% confidence interval (CI): $3.24,17.79)$ with an increase of $10 \mathrm{ppb}$ of $\mathrm{NO}_{2}$. The effect estimates of CMAQ- $\mathrm{NO}_{2}$ were similar to those of AQM-NO assessed in patients living within $3 \mathrm{~km}$ from the nearest AQM station. Even within $1 \mathrm{~km}$, the CI estimate obtained from the CMAQ was much narrower than from AQM (44.18-49.54 vs. 7.02-64.75). However, the association of $\mathrm{AQM}-\mathrm{NO}_{2}$ with $\mathrm{AD}$ symptoms of patients living beyond $3 \mathrm{~km}$ was not positive, whereas that of $\mathrm{CMAQ}-\mathrm{NO}_{2}$ maintained positive. In conclusion, exposure to ambient $\mathrm{NO}_{2}$ is significantly associated with aggravation of AD symptoms in young children. In addition, our study suggests that exposure assessment of $\mathrm{NO}_{2}$ using measurement data obtained from monitoring stations far from residential locations can lead to misclassification bias.
\end{abstract}

Keywords: atopic dermatitis; nitrogen dioxide; air pollution; air pollutants; risk assessment; environmental exposure; child

\section{Introduction}

Exposure assessment is an important component of epidemiologic studies investigating the impact of air pollution on human health. Many investigators have conducted measurements at air quality 
monitoring (AQM) stations to characterize exposure to ambient air pollutants at a population level [1]. However, such monitoring stations offer limited spatial resolution and may only be useful when estimating exposure close to the AQM stations [2]. The characteristics of air pollutants (e.g., chemical components and particle properties) vary spatially [3], and their concentrations may differ depending on the distance from the AQM stations. Therefore, monitoring data obtained from stations located at a large distance from residential places may lead to misclassification bias [4,5].

Air quality modeling with high spatial and temporal resolution can be used to improve exposure assessment, especially for study populations that are located far from the AQM stations [4]. The community multiscale air quality (CMAQ) modeling system is a sophisticated, regional air quality model capable of estimating the concentrations of air pollutants on a local, regional, or continental scale [6]. The CMAQ combines inputs obtained from meteorological and emissions models. Based on this information, the CMAQ system simulates chemical and physical events to analyze pollutant transformation, transport, and fate. Compared to approaches that rely exclusively on monitoring data, the CMAQ data offer improved spatial coverage, and greater spatial and temporal resolution [4]. Based on the perceived advantages, the modeled data obtained from CMAQ system can be used in epidemiologic studies and compared to evaluate the results based on the AQM measurements.

Atopic dermatitis (AD) is a chronic inflammatory skin disease that is most prevalent in early childhood. During the past few decades, the prevalence of AD in children has increased in both developing and developed countries. AD negatively affects quality of life in both patients and their families [7-9]. Because of its increasing prevalence and the risk of progression to respiratory allergies, the management of $\mathrm{AD}$ is an important public health issue. Many environmental factors, including air pollution, have been reported to induce or aggravate $\mathrm{AD}[7,10,11]$. In previous studies, elevated outdoor concentrations of particulate matter with a diameter $\leq 10 \mu \mathrm{m}\left(\mathrm{PM}_{10}\right)$ were significantly associated with increased symptoms of $\mathrm{AD}[12,13]$. Ambient nitrogen dioxide $\left(\mathrm{NO}_{2}\right)$ is another potential risk factor. Nitrogen dioxide generates free radicals, which lead to oxidation of amino acids and peroxidation of polyunsaturated fatty acids [14,15]. An epidemiologic study of 4907 French children residing at their current address for 3 years or longer reported a significant association between lifetime eczema and $\mathrm{NO}_{2}$ exposure [16]. A multivariate logistic regression model revealed that the higher mean annual level of $\mathrm{NO}_{2}$ was significantly associated with the prevalence of eczema in US children [17].

We, therefore, investigated the reliability of $\mathrm{NO}_{2}$ measurements from the AQM stations with low spatial resolution in epidemiologic studies focusing on the acute effects of short-term exposure to ambient $\mathrm{NO}_{2}$ on $\mathrm{AD}$ symptoms in young children. Towards this end, we stratified the AQM measurements based on distance from the residential places to the monitoring stations, and estimated the effects of ambient $\mathrm{NO}_{2}$ on $\mathrm{AD}$ symptoms. We also compared the effect sizes based on AQM data with those based on CMAQ modeling estimates.

\section{Methods}

\subsection{Study Design}

A longitudinal study was designed to assess exposure to $\mathrm{NO}_{2}$ and to evaluate the association between the exposure to $\mathrm{NO}_{2}$ and $\mathrm{AD}$ symptoms in children. A total of 128 young children (78 males and 50 females $<6$ years old) with AD living in Seoul Metropolitan Area, Korea were recruited as a panel. These patients were followed between April and July 2014. This study period included spring and summer, during which the highest and the lowest symptom scores of the year were observed, respectively [18]. Exposure to $\mathrm{NO}_{2}$ was assessed by two methods: (1) collection of measurements at AQM stations selecting the nearest stations to the residential locations, and (2) CMAQ modeling with high spatial resolution. We then evaluated the effects of $\mathrm{NO}_{2}$ on $\mathrm{AD}$ symptoms and compared the effects of subgroups stratified by distance from the residential location to the monitoring stations. 
Written informed consent was obtained from each participant and his/her parents or guardians. Study protocols were reviewed and approved by the Institutional Review Board (IRB) at Samsung Medical Center (IRB No: 2013-05-009).

\subsection{Exposure Assessment of $\mathrm{NO}_{2}$}

To estimate $\mathrm{NO}_{2}$ exposure based on AQM station $\left(\mathrm{AQM}-\mathrm{NO}_{2}\right)$, we obtained hourly $\mathrm{NO}_{2}$ concentrations from 60 national AQM stations in the Seoul Metropolitan Area. $\mathrm{NO}_{2}$ is routinely monitored at hourly intervals using the chemiluminescence method (detection limit of $0.1 \mathrm{ppb}$ ) by the Korean Ministry of the Environment. Based on the hourly data, the daily $24 \mathrm{~h}$ average concentrations of $\mathrm{NO}_{2}$ were calculated for each AQM station. The $\mathrm{NO}_{2}$ values from the station nearest to each subject's home address were used to measure the daily exposure for each subject. The average distance between the participants' residences and the nearest AQM station was $2.03 \pm 1.06 \mathrm{~km}$, ranging from $0.28 \mathrm{~km}$ to $5.73 \mathrm{~km}$.

To obtain a high-resolution concentration of $\mathrm{NO}_{2}$, we used the CMAQ modeling system (ver.5.0.2) (CMAQ-NO ${ }_{2}$ ), which was developed by the United States Environmental Protection Agency (USEPA) [19]. The CMAQ model was run between April and July 2014 in a nested mode under 27, 9, 3, and $1 \mathrm{~km}$ horizontal grid dimensions (D1: $118 \times 125$, D2: $67 \times 79$; D3: $55 \times 49$; and D4: $49 \times 49$ ). The fine-scale innermost domain (D4) was applied to the target area covering the Seoul Metropolitan Area. The study area, residences of the AD patients, and the four modeling domains are shown in Figure 1.

The Advanced Research Weather Research and Forecasting model (WRF) ver. 3.6 [20] was used as the meteorological driver of the CMAQ modeling system. The WRF model was configured with 43 vertical layers, with up to $100 \mathrm{hPa}$ and an approximate thickness of $30 \mathrm{~m}$ at the lowest level (sigma layer $=0.996)$. The simulations were conducted using the initial/lateral boundary conditions generated by interpolating the National Center for Environmental Prediction (NCEP) Final (FNL) Operational data $\left(1^{\circ}, 6 \mathrm{~h}\right.$ interval) (NCEP, 2000). We considered the detailed topography and land use in Korea for the WRF model using high-resolution data obtained from the Korean Environmental Geographic Information System (EGIS, 2019). Appropriate physical parameterization schemes were employed to simulate the meteorological fields over the Korean peninsula [21]. The 27 and $9 \mathrm{~km}$ grid scales were adjusted for nudging of winds.

The emission estimates for the CMAQ in the model-ready grid scale were developed using the Sparse Matrix Operator Kernel Emissions system (SMOKE; https://www.cmascenter.org/ smoke). The anthropogenic emission inventory consists of the Intercontinental Chemical Transport Experiment-Phase B (INTEX-B) [22] for Asia (i.e., China, Japan, and North Korea) and the 2012 Clean Air Policy Support System (CAPSS) national emission inventory [23] for South Korea. Biogenic emissions over South Korea were calculated using the Biogenic Emission Inventory System model (ver. 3.14) with the Environmental Geographical Information System (http://egis.me.go.kr/egis/) land-use data and the Forest Geographical Information System (http://fgis.forest.go.kr/fgis/) vegetation data provided by the Korea Ministry of Environment and the Korea Forest Service.

The CMAQ chemical transport model (CCTM) was run with 23 vertical layers compressed from the WRF's 43 layers; however, the first 12 layers up to approximately $1 \mathrm{~km}$ were maintained. The CCTM simulation employs the SAPRC99 gas-phase chemical mechanism [24] and AERO5 aerosol module [25]. The initial and boundary conditions of ozone $\left(\mathrm{O}_{3}\right)$ and its precursors for the coarse domain $(18 \mathrm{~km}$ grid) were derived based on the default profile distributed with Models-3/CMAQ by the USEPA. The spatiotemporal variations in $\mathrm{NO}_{2}$ concentrations were simulated using the CMAQ modeling system configured with the aforementioned options. Using the simulated $\mathrm{NO}_{2}$ concentrations in the study area with a $1 \mathrm{~km}$ grid scale (domain D4 in Figure 1), we calculated the daily average values for the first model layer. The values at the nearest grid points to the AD patients' residential locations were then selected as the levels of ambient $\mathrm{NO}_{2}$ exposure. 


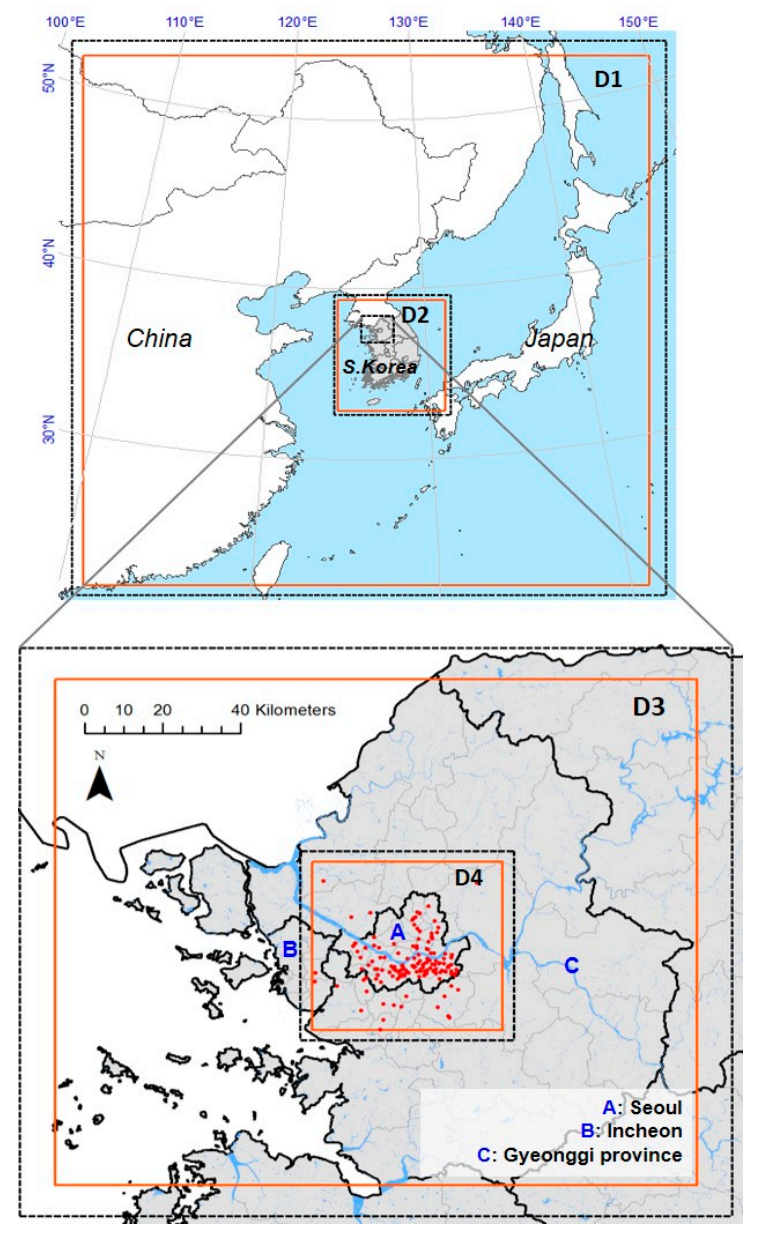

Figure 1. A map of the study area (D4), the residences of the atopic dermatitis patients (red dots), and modeling domains (D1-D4). Black dashed lines indicate the domains for the weather research and forecasting (WRF) model. The solid red line reflects the community multiscale air quality (CMAQ) modeling. The study area (D4) includes Seoul (A) and parts of Incheon (B) and Gyeonggi provinces (C).

\subsection{AD Symptoms}

The diagnosis of AD was determined according to the Hanifin and Rajka criteria [26]. The AD severity was assessed using the Scoring Atopic Dermatitis (SCORAD) scale, ranging from 0-103 [27]. Patients with a SCORAD score $>15$ were enrolled. In children with AD, the total Immunoglobulin $\mathrm{E}$ (IgE) and specific IgE levels against egg white, cow's milk, soybean, wheat and peanut were measured in the peripheral blood using ImmunoCAP (ThermoFisher Scientific Inc., Waltham, MA, USA). Immunoglobulin levels $>0.35 \mathrm{kU} / \mathrm{L}$ were considered positive.

Parents used the Atopic Dermatitis Symptom Score (ADSS), a smartphone-based symptom diary designed to record their daily levels of itching, sleep disturbances, erythema, dryness, oozing, and edema on a scale of 0 to 4 [28]. Patients were considered to manifest AD symptoms when the symptom score was $\geq 2$ for the sum of itching and sleep disturbance scores, plus at least two of the following on the same day: erythema, dryness, edema, or oozing [29]. We matched the daily AD symptoms with $\mathrm{AQM}-\mathrm{NO}_{2}$ and $\mathrm{CMAQ}-\mathrm{NO}_{2}$.

\subsection{Association Analysis}

Repeated measurement of allergic symptoms provides longitudinal data with a binomial distribution. Therefore, a generalized linear mixed model (GLMM) was adopted to estimate the effects of $\mathrm{NO}_{2}$ on $\mathrm{AD}$ symptoms. The GLMM is an extension of the generalized linear model containing 
random effects in addition to the usual fixed effects [30]. In the GLMM model, we treated the $\mathrm{NO}_{2}$ exposure as a fixed effect and each subject as a random effect. We controlled for age, sex, SCORAD at enrollment, the presence of fever ( 0 or 1 , as a proxy of infection), use of topical corticosteroids (TCSs), day of the week, ambient temperature, and relative humidity. The model specifications are as follows:

$$
\ln \left(Y_{i j}\right)=\beta_{0}+\beta_{1}\left(N O_{2}\right)+\sum C F_{i j}+\gamma_{j}(\text { subject })+\varepsilon_{i j}
$$

where $Y_{i j}$ denotes the expected expression of $\mathrm{AD}$ symptoms; $N \mathrm{O}_{2}$ is nitrogen dioxide; and $C F_{i j}$ indicates the confounding factors including ambient temperature and relative humidity, age, sex, day of the week, SCORAD at enrollment, the presence of fever, and use of topical corticosteroids. The random effect for each subject is represented by $\gamma_{j}$.

We stratified the dataset into 5 subgroups based on distance between AQM stations and residential places: $0-1 \mathrm{~km}, 1-2 \mathrm{~km}, 2-3 \mathrm{~km}, 0-3 \mathrm{~km}$ and $>3 \mathrm{~km}$. We then fitted the GLMM models for both AQM and CMAQ by each subgroup to estimate the effects of $\mathrm{NO}_{2}$ on $\mathrm{AD}$ symptoms.

We also examined the lag effects on AD symptoms for up to 5 days after $\mathrm{NO}_{2}$ exposure. LAG1, LAG2, LAG3, LAG4 and LAG5 represent the effects of $\mathrm{NO}_{2}$ on days 1, 2, 3, 4 and 5 post-exposure, respectively. LAG0 indicates the effects on the same day of exposure. Additionally, the effects of AQM-NO $\mathrm{N}_{2}$ on itching, sleep disturbances, erythema, dryness, oozing, and edema were examined. The percent change in risk and $95 \%$ confidence interval (CI) were calculated using regression coefficients and standard errors according to $10 \mathrm{ppb}$ increases of $\mathrm{NO}_{2}$.

All procedures were conducted using the R version 3.6.3 (The Comprehensive R Archive Network: http://cran.r-project.org) with the "lme4" package (version3.1-2) for GLMM model fitting. All tests were two-sided. An alpha level $<0.05$ was considered statistically significant.

\section{Results}

\subsection{Subject Characteristics and AD Symptoms}

A total of 8392 person-days of AD symptoms in 128 children diagnosed with AD were recorded during the four-month study period. Among them, 5300 (63.2\%) and 3092 (36.8\%) person-days were recorded for males and females, respectively. The average age of the study subjects was $1.9 \pm 1.6$ years. Among 8392 person-days of records, the disease symptoms were observed in $44.0 \%$. The presence of AD symptoms was higher in males $(48.7 \%)$ than in females $(36.0 \%)(p \leq 0.0001)$ (Table 1$)$. Based on distance to the nearest AQM station, patients in the subgroups were: $22,50,33$, and 23 every $0-1 \mathrm{~km}$, $1-2 \mathrm{~km}, 2-3 \mathrm{~km}$ and $>3 \mathrm{~km}$, respectively.

Table 1. The characteristics of the study population.

\begin{tabular}{ccccc}
\hline Characteristics & Total & Males & Females & $\boldsymbol{p}_{\text {-Value }}{ }^{\text {a }}$ \\
\hline No. of subjects & 128 & $78(60.9 \%)$ & $50(39.1 \%)$ & \\
Age (year) $^{b}$ & $1.9 \pm 1.6$ & $1.8 \pm 1.5$ & $2.1 \pm 1.7$ & 0.230 \\
SCORAD at enrollment b,c & $30.0 \pm 11.0$ & $30.6 \pm 11.6$ & $29.2 \pm 10.8$ & 0.502 \\
Presence of fever (\%) & 3.8 & 3.4 & 4.6 & 0.010 \\
Use of TCS (\%) d $^{\text {d }}$ & 54.1 & 56.6 & 49.9 & $<0.0001$ \\
Presence of AD symptoms (\%) & 44.0 & 48.7 & 36.0 & $<0.0001$ \\
No. of records (person-days) & 8392 & $5300(63.2 \%)$ & $3092(36.8 \%)$ & \\
\hline
\end{tabular}

a Test for differences between males and females: $t$-test for means of age and SCORAD and Mann-Whitney $U$ test for the presence of fever, use of TCS, and the presence of symptoms; ${ }^{b}$ Data are expressed as means \pm standard deviations; ${ }^{\mathrm{c}}$ SCORAD, Scoring Atopic Dermatitis index; ${ }^{\mathrm{d}} \mathrm{TCS}$, topical corticosteroid; ${ }^{\mathrm{e}}$ AD, atopic dermatitis.

\subsection{Exposure to $\mathrm{NO}_{2}$}

Based on the values obtained from nearest AQM stations, the participants' levels of $\mathrm{NO}_{2}$ were assessed during the study period. The average level of $\mathrm{AQM}-\mathrm{NO}_{2}$ was $31.5 \pm 13.3 \mathrm{ppb}$ and the 
concentrations for each subgroup by distance are shown in Table 2. There was no significant difference between subgroups.

Table 2. Comparison of $\mathrm{NO}_{2}$ exposure levels by AQM measurements and CMAQ predictions.

\begin{tabular}{cccc}
\hline Distance $^{\mathbf{a}}$ & No. (Person-Days) & AQM $^{(\mathbf{p p b})^{\mathbf{b}}}$ & CMAQ (ppb) $^{\mathbf{c}}$ \\
\hline All & 8392 & $31.5 \pm 13.3$ & $22.5 \pm 8.7$ \\
$\leq 1 \mathrm{~km}$ & 1252 & $30.2 \pm 12.9$ & $20.5 \pm 7.8$ \\
$1-2 \mathrm{~km}$ & 3507 & $31.9 \pm 12.7$ & $22.5 \pm 8.7$ \\
$2-3 \mathrm{~km}$ & 2127 & $31.4 \pm 13.3$ & $24.0 \pm 8.8$ \\
$0-3 \mathrm{~km}$ & 1506 & $31.5 \pm 13.0$ & $22.6 \pm 8.7$ \\
$>3 \mathrm{~km}$ & 6886 & $31.5 \pm 14.7$ & $22.0 \pm 8.6$ \\
\hline
\end{tabular}

a Distance between residential place and nearest AQM site; ${ }^{\mathrm{b}} \mathrm{AQM}$, air quality monitoring; ${ }^{\mathrm{c}} \mathrm{CMAQ}$, community multiscale air quality.

The reproducibility of the $\mathrm{NO}_{2}$ concentrations simulated in the CMAQ model was confirmed by comparing data of 60 points in the CMAQ grids locating $60 \mathrm{AQM}$ stations within the study area with measurements collected at the AQM stations. Figure 2 shows that the multi-day evolution of $\mathrm{NO}_{2}$ in the study area was significantly correlated $(\mathrm{r}=0.66)$, with acceptable bias (normalized mean bias $=$ $-20.1 \%$ ) and error (root mean squared error $=12.4 \mathrm{ppb}$ ).

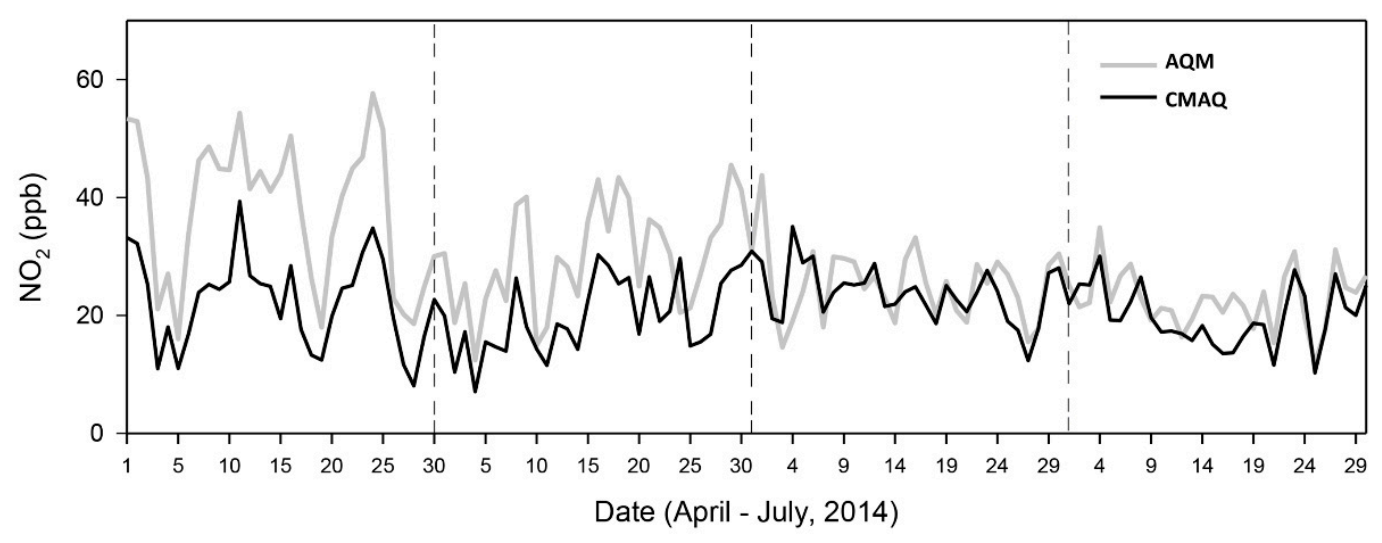

Figure 2. Time series of daily averaged $\mathrm{NO}_{2}$ concentrations by measurements (gray line) and by CMAQ estimates (black line) at the 60 AQM stations.

Based on the results of the CMAQ model, the daily grid-averaged $\mathrm{NO}_{2}$ concentrations were generated during the entire study period, and used to estimate each participant's ambient $\mathrm{NO}_{2}$ exposure. Figure 3 a presents a horizontal distribution of the grid-averaged $\mathrm{NO}_{2}$ concentrations from the CMAQ model of the study area between April and July 2014. Large spatial variations in concentration were observed. The high concentrations were particularly distributed in the southwestern and southeastern area of Seoul, reflecting the impact of high traffic density on ambient $\mathrm{NO}_{2}$ concentration. Figure $3 \mathrm{~b}$ shows a representative example of the estimated daily $\mathrm{NO}_{2}$ exposure level of each study subject on 28 July 2014. It addresses the spatial variation in $\mathrm{NO}_{2}$ levels at each patient's home address according to the results of high-resolution CMAQ modeling.

The average daily CMAQ- $\mathrm{NO}_{2}$ at the patients' residential location during the study period was $22.5 \pm 8.7 \mathrm{ppb}$, which was a lower estimate compared with $\mathrm{AQM}-\mathrm{NO}_{2}(p<0.0001)$. When the AQM-NO $\mathrm{N}_{2}$ was compared with the CMAQ- $\mathrm{NO}_{2}$ for the whole study area and period, the correlation coefficient was $0.51(p<0.0001)$, which was lower than that for the AQM- and CMAQ- $\mathrm{NO}_{2}$ based on 60 points of CMAQ grids located in the $60 \mathrm{AQM}$ stations $(0.66, p<0.0001)$, indicating the discrepancy in the location of residence with $\mathrm{AQM}$ stations in the whole data. 
$a$

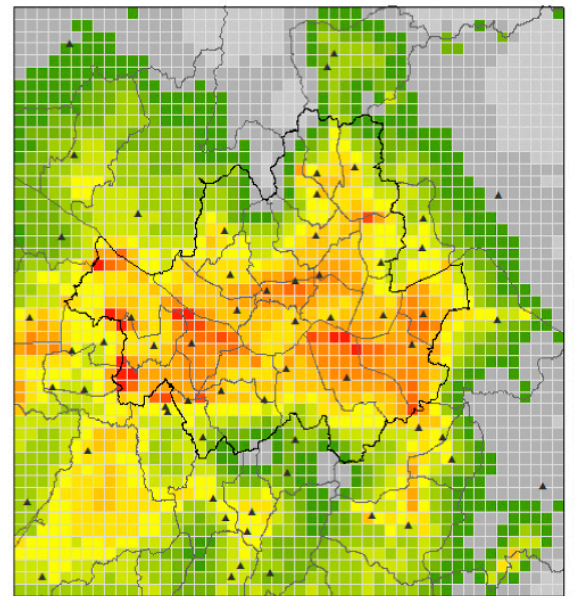

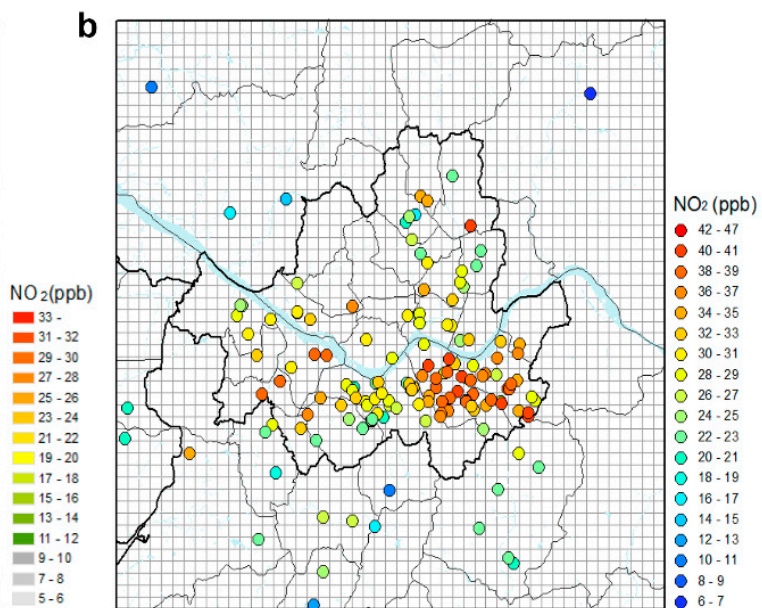

Figure 3. Spatial distribution of $\mathrm{CMAQ}-\mathrm{NO}_{2}$ concentrations. Average $\mathrm{CMAQ}$-modeled $\mathrm{NO}_{2}$ concentrations during the study period (a) and $\mathrm{NO}_{2}$ levels on July 28, 2014 (b). Black triangles indicate 60 AQM stations. Colored circles represent the residential areas of each atopic dermatitis patient.

\subsection{Effect of $\mathrm{NO}_{2}$ on $\mathrm{AD}$ Symptoms}

The effects of ambient $\mathrm{NO}_{2}$ exposure on $\mathrm{AD}$ symptoms by subgroup stratified by distance between residential places and the nearest AQM stations are shown in Table 3. Based on $\mathrm{AQM}-\mathrm{NO}_{2}$, the overall AD symptoms increased by $10.28 \%\left(95 \%\right.$ CI: 3.24, 17.79) with a $10 \mathrm{ppb}$ increase in $\mathrm{NO}_{2}$, while $\mathrm{AD}$ symptoms increased by $13.78 \%(95 \% \mathrm{CI}: 3.49,25.09)$ with a $10 \mathrm{ppb}$ increase in CMAQ-NO $\mathrm{NO}_{2}$. The effect estimates of AQM- and CMAQ-NO $\mathrm{NO}_{2}$ were very similar when assessed using subgroups within $3 \mathrm{~km}$ from the nearest AQM station (Table 3). However, the effect estimate of $\mathrm{AQM}-\mathrm{NO}_{2}$ on $\mathrm{AD}$ symptoms of patients living beyond $3 \mathrm{~km}$ from the monitoring stations was $-3.76 \%$ (95\% CI: $-5.66,-1.83)$. In contrast, a $10 \mathrm{ppb}$ increase in CMAQ- $\mathrm{NO}_{2}$ led to a $13.65 \%$ increase in $\mathrm{AD}$ symptom flares $(95 \% \mathrm{CI}$ : $11.29,16.06)$.

Table 3. Comparison of the effects of AQM- and CMAQ-NO $\mathrm{NO}_{2}$ on atopic dermatitis symptoms according to the distance from the residences to the nearest air quality monitoring sites.

\begin{tabular}{|c|c|c|}
\hline Distance $^{a}$ & $\begin{array}{c}\text { AQM }^{\mathrm{b}} \\
(\% \text { Change }(95 \% \mathrm{CI}))\end{array}$ & $\begin{array}{c}\text { CMAQ }^{c} \\
(\% \text { Change }(95 \% \text { CI }))\end{array}$ \\
\hline All & $10.28(3.24,17.79)$ * & $13.78(3.49,25.09) *$ \\
\hline$\leq 1 \mathrm{~km}$ & $32.79(7.02,64.75)$ * & $46.84(44.18,49.54) *$ \\
\hline $1-2 \mathrm{~km}$ & $6.60(-2.87,17.00)$ & $4.80(-7.88,19.22)$ \\
\hline $2-3 \mathrm{~km}$ & $29.15(10.39,51.11)$ * & $29.67(2.64,63.81)$ * \\
\hline $0-3 \mathrm{~km}$ & $14.21(6.03,23.03)$ * & $13.88(2.56,26.46)$ * \\
\hline$>3 \mathrm{~km}$ & $-3.76(-5.66,-1.83) *$ & $13.65(11.29,16.06)$ * \\
\hline
\end{tabular}

${ }^{a}$ Distance between residential place and nearest AQM site; ${ }^{\mathrm{b}} \mathrm{AQM}$, air quality monitoring; ${ }^{\mathrm{c}} \mathrm{CMAQ}$, community multiscale air quality; ${ }^{*}$ indicates statistically significant with an alpha level $<0.05$.

Figure 4 shows penalized regression curves controlling for age, sex, SCORAD at enrollment, the presence of fever, use of TCS, day of the week, ambient temperature and humidity. The curves describe the relationship between AQM- or CMAQ- $\mathrm{NO}_{2}$ levels and AD symptoms on the same day (LAG0). The AD symptoms increased linearly as ambient $\mathrm{NO}_{2}$ increased when based on whole CMAQ- $\mathrm{NO}_{2}$ (Figure $4 \mathrm{~b}$ ) and AQM-NO $\mathrm{N}_{2}$ for patients living $0-3 \mathrm{~km}$ distant from the AQM stations (Figure 4c). However, the relationship between $\mathrm{AQM}-\mathrm{NO}_{2}$ and $\mathrm{AD}$ symptoms in all patients was not linear. 
a

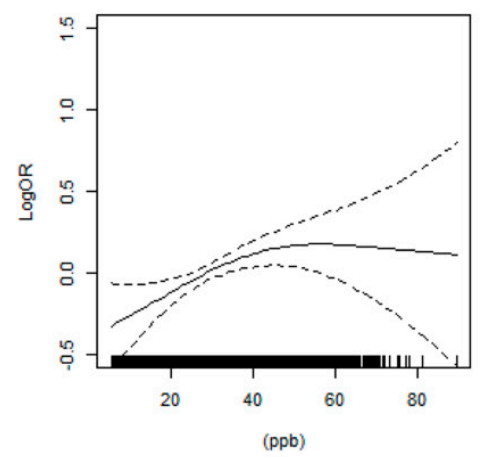

b

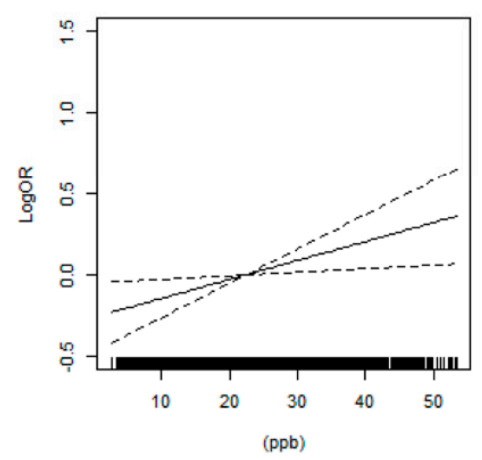

C

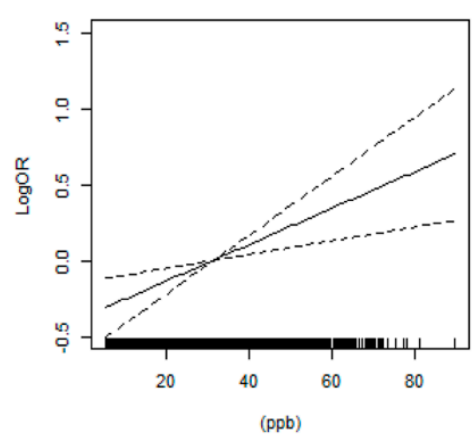

Boys (AQM)

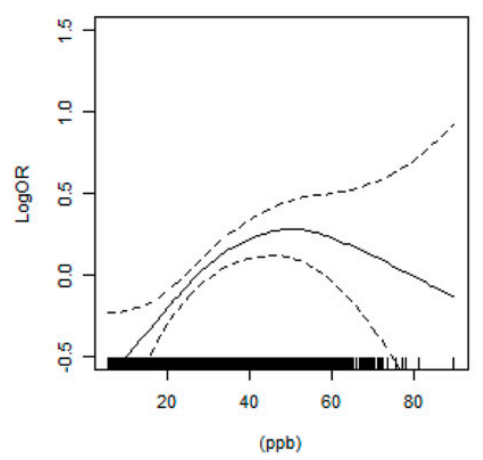

Boys (CMAQ)

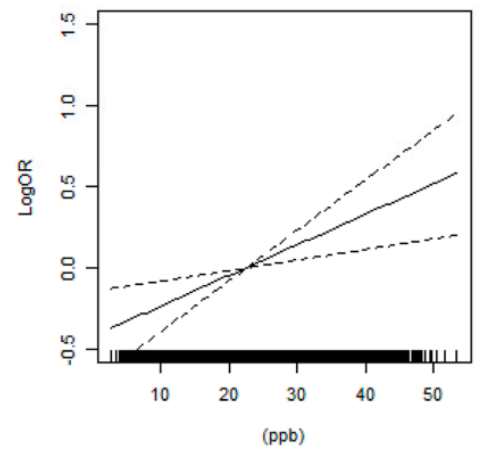

Boys (AQM 0 3 km)

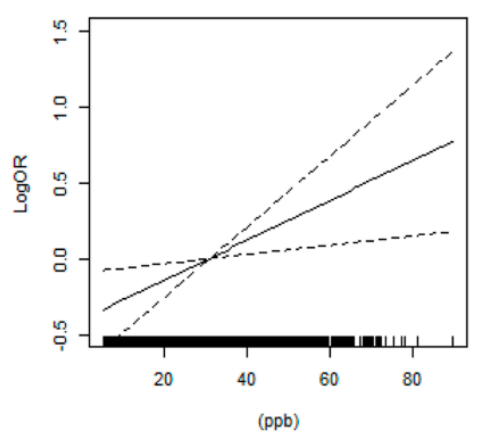

Girls (AQM)

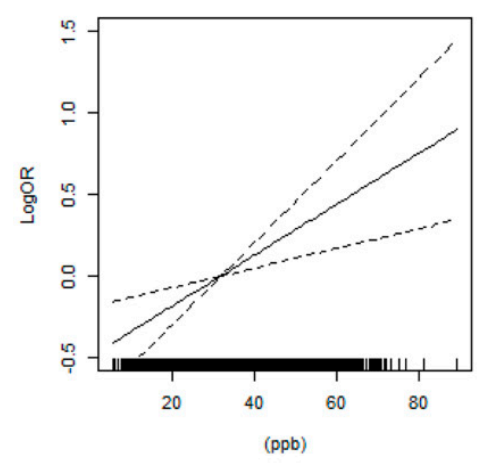

Girls (CMAQ)

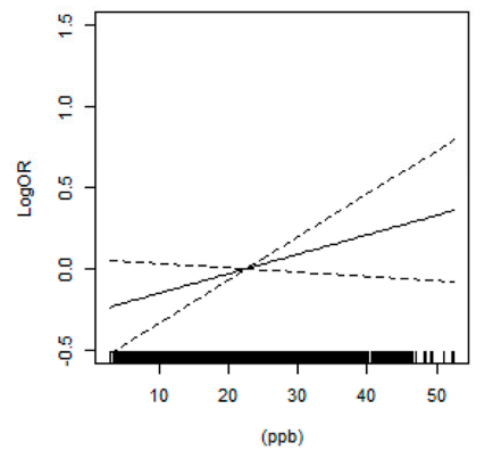

Girls (AQM 0 3 km)

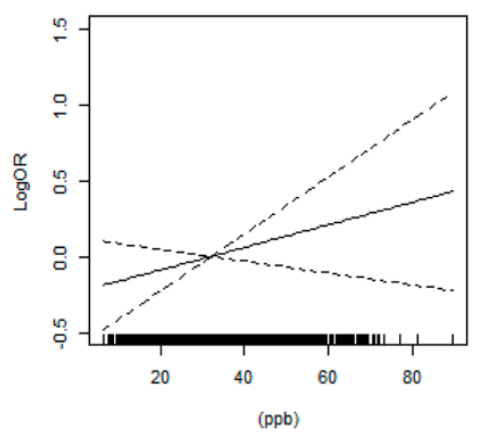

Figure 4. Associations between atopic dermatitis symptoms and the estimated exposure to $\mathrm{NO}_{2}$. Penalized regression curve (solid line) with a 95\% confidence interval (two dashed lines) based on (a) AQM-NO $\mathrm{NO}_{2}$ in all patients, (b) CMAQ- $\mathrm{NO}_{2}$ in all patients, and (c) $\mathrm{AQM}-\mathrm{NO}_{2}$ from a subgroup residing within $3 \mathrm{~km}$ from AQM stations. Statistical analyses were performed after controlling for age, sex, SCORAD at enrollment, the presence of fever, use of topical corticosteroids, day of the week, and ambient temperature and humidity.

Table 4 shows the lag effect of $\mathrm{NO}_{2}$ exposure on AD symptoms as a result of GLMM fitting using the dataset of patients living at a distance of $0-3 \mathrm{~km}$ from the nearest AQM stations. The AQM- and CMAQ-NO $\mathrm{N}_{2}$ showed a very similar pattern in the $0-, 1-, 2-, 3-, 4-, 5-$ day lag effect estimates. In both models, one-day lag was seen in the $\mathrm{NO}_{2}$ effect on $\mathrm{AD}$ symptoms in children, while no significant lag effects of $\mathrm{NO}_{2}$ occurred 2-5 days after exposure (LAG2-LAG5). An increase in AQM-NO ${ }_{2}$ by $10 \mathrm{ppb}$ on a single previous day (LAG1) was significantly associated with an increase in AD symptoms by $12.96 \%$ (95\% CI: $5.28,21.21)$. Interestingly, males appeared to be more sensitive to $\mathrm{NO}_{2}$ exposure than females. The AD symptoms in males increased by $17.48 \%(95 \%$ CI: $6.55,29.54)$ per $10 \mathrm{ppb}$ of AQM-NO increase, whereas the effect in females was not significant $(9.56 \%(95 \% \mathrm{CI}:-2.10,22.61))$. The effects in males were also statistically significant in LAG1 based on AQM-NO ${ }_{2}$, and in LAG0-LAG2 based on $\mathrm{CMAQ}-\mathrm{NO}_{2}$. However, none of the results was statistically significant for females. 
Table 4. The lag effects of AQM- and CMAQ-NO 2 on AD symptoms $(0-3 \mathrm{~km})^{\text {a }}$.

\begin{tabular}{|c|c|c|c|}
\hline & Lag Time $^{b}$ & $\begin{array}{c}\text { AQM }^{\mathrm{c}} \\
(\% \text { Change }(95 \% \mathrm{CI}))\end{array}$ & $\begin{array}{c}\text { CMAQ }^{d} \\
(\% \text { Change }(95 \% \mathrm{CI}))\end{array}$ \\
\hline \multirow{6}{*}{ Both } & LAG0 & $14.21(6.03,23.03)$ * & $13.88(2.56,26.46)$ * \\
\hline & LAG1 & $12.96(5.28,21.21)$ * & $13.06(2.27,24.99)$ * \\
\hline & LAG2 & $5.92(-1.29,13.66)$ & $8.51(-2.03,20.18)$ \\
\hline & LAG3 & $3.14(-4.08,10.92)$ & $0.42(-9.80,11.80)$ \\
\hline & LAG4 & $4.67(-2.62,12.51)$ & $0.45(-9.58,11.59)$ \\
\hline & LAG5 & $2.22(-4.79,9.75)$ & $2.43(-7.58,13.53)$ \\
\hline \multirow{6}{*}{ Males } & LAG0 & $17.48(6.55,29.54)$ * & $18.92(3.90,36.11)$ * \\
\hline & LAG1 & $20.17(9.27,32.15)$ * & $20.68(5.51,38.03)$ * \\
\hline & LAG2 & $8.43(-1.36,19.20)$ & $16.41(1.72,33.20)$ * \\
\hline & LAG3 & $4.07(-5.58,14.71)$ & $1.33(-12.10,16.80)$ \\
\hline & LAG4 & $5.38(-4.42,16.19)$ & $4.34(-9.18,19.87)$ \\
\hline & LAG5 & $4.49(-5.10,15.06)$ & $8.56(-5.59,24.84)$ \\
\hline \multirow{6}{*}{ Females } & LAG0 & $9.56(-2.10,22.61)$ & $7.44(-8.78,26.53)$ \\
\hline & LAG1 & $4.59(-5.91,16.25)$ & $5.33(-9.97,23.23)$ \\
\hline & LAG2 & $2.81(-7.58,14.37)$ & $0.44(-14.33,17.77)$ \\
\hline & LAG3 & $2.09(-8.52,13.93)$ & $0.52(-14.77,18.55)$ \\
\hline & LAG4 & $3.65(-6.92,15.43)$ & $-3.72(-18.17,13.28)$ \\
\hline & LAG5 & $-0.71(-10.64,10.33)$ & $-4.91(-18.76,11.30)$ \\
\hline
\end{tabular}

\footnotetext{
a Values are percent changes in the presence of AD symptoms caused by $10 \mathrm{ppb}$ increases in $\mathrm{NO}_{2}$ and all effect estimates were results from patients living under $3 \mathrm{~km}$ distant from nearest AQM sites; ${ }^{\mathrm{b}}$ LAG0, effect of $\mathrm{NO}_{2}$ exposure on AD symptoms on the same day; LAG1, LAG2, LAG3, LAG4 and LAG5, symptoms lagged by 1, 2, 3, 4 and 5 days after exposure, respectively; ${ }^{\mathrm{C}} \mathrm{CMAQ}$ : community multiscale air quality; ${ }^{\mathrm{d}} \mathrm{AQM}$ : air quality monitoring; * statistically significant with an alpha level $<0.05$.
}

Table 5 shows the effect of $\mathrm{AQM}-\mathrm{NO}_{2}$ on each $\mathrm{AD}$ symptom in results of fitting Poisson regression model with random effect using the dataset of patients living at a distance of $0-3 \mathrm{~km}$ from the nearest $\mathrm{AQM}$ stations. Itching and sleep disturbance were significantly increased according to an increase in $\mathrm{NO}_{2}$.

Table 5. Effects of $A Q M-N_{2}$ on each $A D$ symptom $(0-3 \mathrm{~km})^{a}$.

\begin{tabular}{cc}
\hline Symptom & \% Change (95\% CI) \\
\hline Itching & $2.53(0.50,4.60)^{*}$ \\
Sleep disturbance & $3.62(1.05,6.26)^{*}$ \\
Erythema & $0.45(-1.62,2.56)$ \\
Dryness & $1.84(-0.37,4.09)$ \\
Edema & $1.96(-1.67,5.72)$ \\
Oozing & $-9.11(-15.29,-2.47)$ \\
\hline
\end{tabular}

\footnotetext{
a Values are percent changes in the presence of AD symptoms caused by 10 ppb increases in NO2.; * statistically significant with an alpha level $<0.05$.
}

\section{Discussion}

In our longitudinal study using AQM measurements and high-resolution CMAQ predictions, we found that $A Q M$ data with low spatial resolution obtained from stations distant from residential areas resulted in misclassification of exposure and misunderstanding of the health effect. For example, when we compared the results of AQM-and CMAQ-NO $\mathrm{N}_{2}$ estimates in the GLMM models after selecting 23 subjects residing more than $3 \mathrm{~km}$ away from the nearest $A Q M$ stations, the $A Q M-N_{2}$ showed a negative relationship with $\mathrm{AD}$ symptoms. The effect of the CMAQ-modeled $\mathrm{NO}_{2}$ on $\mathrm{AD}$ symptoms from the dataset was, however, positive (Table 3). The AQM data of residents living far from the $\mathrm{AQM}$ stations may not be reliable for use in epidemiologic studies. Conversely, the AQM-NO measurements can be used for exposure assessment in epidemiologic studies if study participants 
lived within $3 \mathrm{~km}$ from the nearest AQM stations in this study area. Therefore, the use of AQM measurements in the evaluation of health effects of $\mathrm{NO}_{2}$ on $\mathrm{AD}$ should be attended with caution. Indeed, the concentrations of $\mathrm{CMAQ}-\mathrm{NO}_{2}$ match well with those of $\mathrm{AQM}-\mathrm{NO}_{2}$ in areas within $3 \mathrm{~km}$ of the study stations, and $\mathrm{CMAQ}-\mathrm{NO}_{2}$ consistently showed an adverse effect on AD symptoms even in subgroups residing beyond $3 \mathrm{~km}$ of distance from the monitoring stations. Considering that CMAQ modeled $\mathrm{NO}_{2}$ estimates were based on grid points less than $0.7 \mathrm{~km}$ from residential places, they are reliable and useful in epidemiologic studies particularly for residents with no measurement.

Our study demonstrated that high levels of ambient $\mathrm{NO}_{2}$ were significantly associated with increased AD symptom flares in young children. The harmful effects of ambient $\mathrm{NO}_{2}$ were acute on the same day, but were also delayed for up to one day. This finding is consistent with a previous study, in which transepidermal water loss was significantly increased in patients with $\mathrm{AD}$ after $\mathrm{NO}_{2}$ exposure [14]. Interestingly, there was a distinct difference in the effects of $\mathrm{NO}_{2}$ on $\mathrm{AD}$ symptoms between males and females. Although the mechanism is not clear, it may be attributed to physiological differences. It is well known that gender influences lung development and physiology, which play a major role in diseases from early life [31]. Males tend to have a greater inhalation capacity than females: The inhalation rate of males aged 1-2 years was $0.48 \mathrm{~m}^{3} / \mathrm{kg} /$ day on average, compared with $0.45 \mathrm{~m}^{3} / \mathrm{kg} /$ day in females [32]. This rate discrepancy implies that males also inhale $\mathrm{more}^{\mathrm{NO}} \mathrm{NO}_{2}$ than females. There may also be gender differences in dermal absorption and toxicity, according to physiological pharmacokinetic (PBPK) modeling [33,34]. Immune development, infection, and gut microbiota are known to affect males and females differently [35,36]. In general, males tend to be more physically active than females, which may also influence the harmful effects of $\mathrm{NO}_{2}$ on AD symptoms. Ultimately, further detailed exposure assessments, including time-activity patterns and toxicological studies, with gender specific perspectives are required to elucidate these gender differences.

The strength of our study is that the usefulness of monitored $\mathrm{NO}_{2}$ was investigated by stratifying by distance from stations and comparing the health effects of the monitored $\mathrm{NO}_{2}$ with the $\mathrm{CMAQ}-\mathrm{NO}_{2}$ with high spatial resolution, along with a smartphone-based daily symptom diary. This method allowed us to assess individual $\mathrm{NO}_{2}$ exposure and symptom changes on a daily basis, consequently reflecting the detrimental effects of $\mathrm{NO}_{2}$ on $\mathrm{AD}$ at the population level. However, the CMAQ values are somewhat underestimated compared to the measurements from the AQM stations (Table 2). This discrepancy may be attributed to errors in $\mathrm{NO}_{2}$ emission estimates, as well as uncertainty in $\mathrm{NO}_{2}$ chemical loss rates [37,38].

This study has limitations. First, we did not consider the indoor $\mathrm{NO}_{2}$ level, despite the fact that children spend most of their time indoors. However, traffic emissions are the major source of $\mathrm{NO}_{2}$ in Seoul, and indoor $\mathrm{NO}_{2}$ level is very dependent on outdoor conditions [39]. Therefore, presumably, it had no significant impact on the results, although our study did not evaluate the exposure to indoor $\mathrm{NO}_{2}$. Second, we did not include ambient particulate matters (PMs) and $\mathrm{O}_{3}$ in the GLMMs as confounders although ambient $\mathrm{PMs}$ and $\mathrm{O}_{3}$ are associated with AD symptoms in children [29]. The GLMM results with $\mathrm{PM}_{10}$ and $\mathrm{O}_{3}$ could be biased if the measurements of exposure to $\mathrm{PM}_{10}$ and $\mathrm{O}_{3}$ were included. Indeed, when we included $\mathrm{PM}_{10}$ and $\mathrm{O}_{3}$ in the GLMM model to estimate the AQM-NO $\mathrm{N}_{2}$ effect on AD symptoms in participants living within $3 \mathrm{~km}$ from the nearest AQM stations, the result was very similar to that of a model without $\mathrm{PM}_{10}$ and $\mathrm{O}_{3}$. In the result of modeling with $\mathrm{PM}_{10}$ and $\mathrm{O}_{3}$, the AD symptoms increased by $12.39 \%$ (95\% CI: 3.20, 22.40) due to 10 ppb of increase in AQM-NO $\mathrm{N}_{2}$, while those of the model without $\mathrm{PM}_{10}$ and $\mathrm{O}_{3}$ increased by $14.21 \%(95 \% \mathrm{CI}: 6.03,23.03)$, as shown in Table 3. Therefore, the results from the GLMMs for the whole groups in this study are not changed substantially assuming accurate exposure assessment of $\mathrm{PM}_{10}$ and $\mathrm{O}_{3}$. Finally, CMAQ predictions are of limited value. Uncertainties in CMAQ-ready inputs of meteorological and emission predictions and incomplete lateral boundary conditions for a nested modeling can lead to bias in the simulated $\mathrm{NO}_{2}$ concentrations. These uncertainties and incomplete input data could especially increase the inaccuracy of $\mathrm{NO}_{2}$ predictions when a long-range transport of air pollutants frequently occurs over the northeastern Asia in spring. The relatively large differences between $\mathrm{CMAQ}$ and monitored $\mathrm{NO}_{2}$ 
concentrations in April and May shown in Figure 2 could be a result from this long-range transport contribution that CMAQ did not reproduce.

\section{Conclusions}

Exposure assessment of $\mathrm{NO}_{2}$ using measurement data obtained from monitoring stations far from residential locations can lead to misclassification bias. Our results also suggest that exposure to ambient $\mathrm{NO}_{2}$ is significantly associated with aggravation of $\mathrm{AD}$ symptoms in young children with lag effects, particularly in males. Efforts to reduce ambient $\mathrm{NO}_{2}$ may be required to control disease flares in patients with pre-existing AD.

Author Contributions: K.A., Y.-M.K., and I.O. conceptualized the study. Y.-M.K. and I.O. designed the methods. J.K. and K.A. enrolled and followed the patients. Y.-M.K., I.O., and Y.-H.K. collected and analyzed data. J.K. and K.A. reviewed the clinical data. Y.-M.K., I.O., J.K., and K.A. interpreted the results. Y.-M.K. and I.O. wrote the manuscript. All authors have read and agreed to the published version of the manuscript.

Funding: This research was funded by the Ministry of Environment, Republic of Korea as the Environmental Health Action Program (Grant number: 2013001360002) and the Environmental Health Center.

Acknowledgments: We are grateful to all of those who recorded symptom diary data.

Conflicts of Interest: The authors declare no conflict of interest.

\section{References}

1. Baxter, L.K.; Dionisio, K.L.; Burke, J.; Ebelt Sarnat, S.; Sarnat, J.A.; Hodas, N.; Rich, D.Q.; Turpin, B.J.; Jones, R.R.; Mannshardt, E.; et al. Exposure prediction approaches used in air pollution epidemiology studies: Key findings and future recommendations. J. Expo. Sci. Environ. Epidemiol. 2013, 23, 654-659. [CrossRef]

2. Sarnat, S.E.; Klein, M.; Peel, J.L.; Mulholland, J.; Sarnat, J.A.; Flanders, W.D.; Waller, L.A.; Tolbert, P.E. Spatial considerations in a study of ambient air pollution and cardiorespiratory emergency department visits. Epidemiology 2006, 17, S242-S243. [CrossRef]

3. Bell, M.L.; Dominici, F.; Ebisu, K.; Zeger, S.L.; Samet, J.M. Spatial and temporal variation in PM(2.5) chemical composition in the United States for health effects studies. Environ. Health Perspect. 2007, 115, 989-995. [CrossRef]

4. Bravo, M.A.; Fuentes, M.; Zhang, Y.; Burr, M.J.; Bell, M.L. Comparison of exposure estimation methods for air pollutants: Ambient monitoring data and regional air quality simulation. Environ. Res. 2012, 116, 1-10. [CrossRef]

5. Yarza, S.; Hassan, L.; Shtein, A.; Lesser, D.; Novack, L.; Katra, I.; Kloog, I.; Novack, V. Novel approaches to air pollution exposure and clinical outcomes assessment in environmental health studies. Atmosphere 2020, 11, 122. [CrossRef]

6. Byun, D.; Schere, K. Review of the governing equations, computational algorithms, and other components of the Models-3 community multiscale air quality (CMAQ) modeling system. Appl. Mech. Rev. 2006, 59, 51-77. [CrossRef]

7. Ahn, K. The role of air pollutants in atopic dermatitis. J. Allergy Clin. Immunol. 2014, 134, 993-999. [CrossRef] [PubMed]

8. Shaw, T.E.; Currie, G.P.; Koudelka, C.W.; Simpson, E.L. Eczema prevalence in the United States: Data from the 2003 National Survey of Children's Health. J. Investig. Dermatol. 2011, 131, 67-73. [CrossRef] [PubMed]

9. Williams, H.; Stewart, A.; von Mutius, E.; Cookson, W.; Anderson, H.R. International Study of Asthma; Allergies in Childhood Phase; One Three Study Groups. Is eczema really on the increase worldwide? J. Allergy Clin. Immunol. 2008, 121, 947-954. [CrossRef]

10. Altug, H.; Gaga, E.O.; Dogeroglu, T.; Ozden, O.; Ornektekin, S.; Brunekreef, B.; Meliefste, K.; Hoek, G.; Van Doorn, W. Effects of air pollution on lung function and symptoms of asthma, rhinitis and eczema in primary school children. Environ. Sci. Pollut. Res. Int. 2013, 20, 6455-6467. [CrossRef]

11. Sole, D.; Camelo-Nunes, I.C.; Wandalsen, G.F; Pastorino, A.C.; Jacob, C.M.; Gonzalez, C.; Wandalsen, N.F.; Rosario Filho, N.A.; Fischer, G.B.; Naspitz, C.K. Prevalence of symptoms of asthma, rhinitis, and atopic eczema in Brazilian adolescents related to exposure to gaseous air pollutants and socioeconomic status. J. Investig. Allergol. Clin. Immunol. 2007, 17, 6-13. [PubMed] 
12. Kim, J.; Kim, E.H.; Oh, I.; Jung, K.; Han, Y.; Cheong, H.K.; Ahn, K. Symptoms of atopic dermatitis are influenced by outdoor air pollution. J. Allergy Clin. Immunol. 2013, 132, 495-498. [CrossRef] [PubMed]

13. Kim, Y.M.; Kim, J.; Han, Y.; Lee, B.J.; Choi, D.C.; Cheong, H.K.; Jeon, B.H.; Oh, I.; Bae, G.N.; Lee, J.Y.; et al. Comparison of diverse estimation methods for personal exposure to air pollutants and associations with allergic symptoms: The Allergy \& Gene-Environment Link (ANGEL) study. Sci. Total Environ. 2017, 579, 1127-1136.

14. Eberlein-Konig, B.; Przybilla, B.; Kuhnl, P.; Pechak, J.; Gebefugi, I.; Kleinschmidt, J.; Ring, J. Influence of airborne nitrogen dioxide or formaldehyde on parameters of skin function and cellular activation in patients with atopic eczema and control subjects. J. Allergy Clin. Immunol. 1998, 101, 141-143. [CrossRef]

15. Ji, H.; Li, X.K. Oxidative Stress in Atopic Dermatitis. Oxid. Med. Cell. Longev. 2016, 2016, 2721469. [CrossRef] [PubMed]

16. Penard-Morand, C.; Raherison, C.; Charpin, D.; Kopferschmitt, C.; Lavaud, F.; Caillaud, D.; Annesi-Maesano, I. Long-term exposure to close-proximity air pollution and asthma and allergies in urban children. Eur. Respir. J. 2010, 36, 33-40. [CrossRef]

17. Kathuria, P.; Silverberg, J.I. Association of pollution and climate with atopic eczema in US children. Pediatr. Allergy Immunol. 2016, 27, 478-485. [CrossRef]

18. Kim, M.; Kim, Y.M.; Lee, J.Y.; Yang, H.K.; Kim, H.; Cho, J.; Ahn, K.; Kim, J. Seasonal variation and monthly patterns of skin symptoms in Korean children with atopic eczema/dermatitis syndrome. Allergy Asthma Proc. 2017, 38, 294-299. [CrossRef]

19. Byun, D.; Ching, J.K.S. Science Algorithms of the EPA Models-3 Community Multiscale Air Quality (CMAQ) Modeling System; EPA-600/R99/030; Office of Research and Development, U.S. EPA.: Washington, DC, USA, 1999.

20. Skamarock, W.C.; Klemp, J.B.; Dudhia, J.; Gill, D.O.; Barker, D.M.; Duda, M.G.; Huang, X.Y.; Wand, W.; Powers, J.G. A Description of the Advanced Research WRF Version 3 (No. NCAR/TN-475+STR); University Corporation for Atmospheric Research: Boulder, CO, USA, 2008.

21. National Institute of Environmental Research (NIER). Studies on the Optimization Method for Improving the Accuracy of Air Quality Modeling; NIER-SP2013-210; National Institute of Environmental Research (NIER): Incheon, Korea, 2013.

22. Zhang, Q.; Streets, D.G.; Carmichael, G.R.; He, K.; Huo, H.; Kannari, A.; Klimont, Z.; Park, I.; Reddy, S.; $\mathrm{Fu}$, J.S.; et al. Asian emissions in 2006 for the NASA INTEX-B mission. Atmos. Chem. Phys. Discuss 2009, 9, 5131-5153. [CrossRef]

23. National Institute of Environmental Research (NIER). National Air Pollutants Emission; NIER-GP2014-392; National Institute of Environmental Research (NIER): Incheon, Korea, 2014.

24. Cater, W.P.L. Documentation of the SAPRC-99 chemical mechanism for VOC reactivity assessment. Final Report to California Air Resources Board. Univ. Calif. Riverside 2000, 8, 92-329.

25. Carlton, A.G.; Bhave, P.V.; Napelenok, S.L.; Edney, E.O.; Sarwar, G.; Pinder, R.W.; Pouliot, G.A.; Houyoux, M. Model representation of secondary organic aerosol in CMAQv4.7. Environ. Sci. Technol. 2010, 44, 8553-8560. [CrossRef] [PubMed]

26. Hanifin, J.; Rajka, G. Diagnostic features of atopic dermatitis. Acta. Derm. Venereol. 1980, 92, $44-47$.

27. European Task Force on Atopic Dermatitis. Severity scoring of atopic dermatitis: The SCORAD index. Consensus Report of the European Task Force on Atopic Dermatitis. Dermatology 1993, 186, 23-31. [CrossRef] [PubMed]

28. Lee, J.Y.; Kim, M.; Yang, H.K.; Kim, H.M.; Cho, J.; Kim, Y.M.; Lim, I.S.; Cheong, H.K.; Kim, H.S.; Sohn, I.; et al. Reliability and validity of the Atopic Dermatitis Symptom Score (ADSS). Pediatr. Allergy Immunol. 2018, 29, 290-295. [CrossRef] [PubMed]

29. Kim, Y.M.; Kim, J.; Han, Y.; Jeon, B.H.; Cheong, H.K.; Ahn, K. Short-term effects of weather and air pollution on atopic dermatitis symptoms in children: A panel study in Korea. PLoS ONE 2017, 12, e0175229. [CrossRef] [PubMed]

30. Breslow, N.E.; Clayton, D.G. Approximate inference in generalized linear mixed models. J. Am. Statist. Assoc. 1993, 88, 9-25.

31. Carey, M.A.; Card, J.W.; Voltz, J.W.; Arbes, S.J., Jr.; Germolec, D.R.; Korach, K.S.; Zeldin, D.C. It's all about sex: Gender, lung development and lung disease. Trends Endocrinol. Metab. 2007, 18, 308-313. [CrossRef] 
32. US Environmental Protection Agency (USEPA). Exposure Factors Handbook; National Center for Environmental Assessment: Washington, DC, USA, 2011.

33. Arbuckle, T.E. Are there sex and gender differences in acute exposure to chemicals in the same setting? Environ. Res. 2006, 101, 195-204. [CrossRef]

34. Meibohm, B.; Beierle, I.; Derendorf, H. How important are gender differences in pharmacokinetics? Clin. Pharmacokinet. 2002, 41, 329-342. [CrossRef]

35. Fish, E.N. The X-files in immunity: Sex-based differences predispose immune responses. Nat. Rev. Immunol. 2008, 8, 737-744. [CrossRef]

36. Uekert, S.J.; Akan, G.; Evans, M.D.; Li, Z.; Roberg, K.; Tisler, C.; Dasilva, D.; Anderson, E.; Gangnon, R.; Allen, D.B.; et al. Sex-related differences in immune development and the expression of atopy in early childhood. J. Allergy Clin. Immunol. 2006, 118, 1375-1381. [CrossRef] [PubMed]

37. Han, K.M.; Lee, C.K.; Lee, J.; Kim, J.; Song, C.H. A comparison study between model-predicted and OMI-retrieved tropospheric $\mathrm{NO}_{2}$ columns over the Korean peninsula. Atmos. Environ. 2011, 45, 2962-2971. [CrossRef]

38. Han, K.M.; Song, C.H.; Ahn, H.J.; Park, R.S.; Woo, J.H.; Lee, C.K.; Richter, A.; Burrows, J.P.; Kim, J.Y.; Hong, J.H. Investigation of NOx emissions and NOx related chemistry in East Asia using CMAQ-predicted and GOME-derived $\mathrm{NO}_{2}$ columns. Atmos. Chem. Phys. Discuss 2009, 9, e1017-e1036. [CrossRef]

39. Lee, J.Y.; Ryu, S.H.; Kim, C.; Bae, G.N. Indoor-to-outdoor pollutant concentration ratio modeling of $\mathrm{CO}_{2}$, $\mathrm{NO}_{2}$, and lung-deposited nanoparticles. Atmos. Pollut. Res. 2016, 7, 664-670. [CrossRef]

(C) 2020 by the authors. Licensee MDPI, Basel, Switzerland. This article is an open access article distributed under the terms and conditions of the Creative Commons Attribution (CC BY) license (http://creativecommons.org/licenses/by/4.0/). 